\title{
MEMBEDAH KARYA \\ ERICA HESTUWAHYUNI \\ MELALUI STUDI BAHASA RUPA
}

\author{
Kurniawati Gautama \\ Program Studi Seni Rupa Intermedia Fakultas Industri Kreatif \\ Universitas Telkom
}

\begin{abstract}
Bahasa Rupa (picture-writing) is an invention of Prof.Dr. Primadi Tabrani to analize the specific character of Eastern tradition which is different from Western. It is a visual communication study in modern and traditional picture-writing system. The modern (western) "bahasa rupa" uses 'close up' format which recognized universally, whereas the traditional (eastern) system such as the relief of Borobudur Temple, Wayang Beber (scroll-painted picture presentations), Balinesse Painting, have specific drawing technique.
\end{abstract}

This essay, will analize an Indonesian and international recognized female painter, Erica Hestuwahyuni, whose artworks show childlike character. As introduction this essay will elaborate the differences between painting and drawing, also Bahasa Rupa theory and character of children drawings.

Key words: bahasa rupa, children drawings, , drawings, psychoanalysis, relief

\section{PENDAHULUAN}

Istilah seni rupa dalam Bahasa Indonesia, apabila di terjemahkan ke dalam bahasa Inggris mengalami kerancuan, yaitu antara visual art dan fine art. Dalam wacana seni rupa pengertian visual art dan fine art dibedakan (Supangkat, 2001:7). Istilah seni rupa dalam pengertian visual art mempunyai lingkup yang lebih luas yaitu mulai dari seni lukis, seni gambar, seni tekstil, seni kriya, seni membuat sepatu dan baju. Sementara seni rupa dalam lingkup fine art, dalam Kamus Umum Bahasa Indonesia hanya meliputi seni lukis, seni patung dan seni grafis. (Supangkat, 2001:11).

Makalah ini membahas cara pembacaan salah satu cabang seni rupa dalam pengertian fine art yaitu seni lukis dan yang membedakannya dengan seni gambar.

Istilah gambar menurut Saneto Yuliman dalam kumpulan tulisannya di Dua Seni Rupa, mempunyai lingkup yang luas yaitu mencakup yang nampak di layar televisi ketika pewawat dihidupkan, yang kelihatan di layar bioskop ketika film main, foto, reproduksi foto, lukisan, peta, denah, grafik, Di kalangan para pelukis, lukisan sering disebut 
gambar. Menurut Jim Supangkat, dalam katalog pameran Drawing, secara sederhana gambar merupakan medium sederhana dengan garis sebagai komponen utama. Dalam proses melukis gambar sering disebut sebagai sketsa atau karya yang belum selesai. Oleh karena itu, gambar sering dipersepsikan sebagai tidak sejajar dengan lukisan. Ketika fotografi belum ditemukan, seni lukis dipandang sebagai mampu merekam kenyataan yang menghasilkan lukisan realistik (meniru citra kenyataan) dan mampu 'menghembuskan nyawa'. Berbeda dengan gambar, karena sifat materialnya, betapapun miripnya, tidak mampu menghasilkan rekaman hidup.

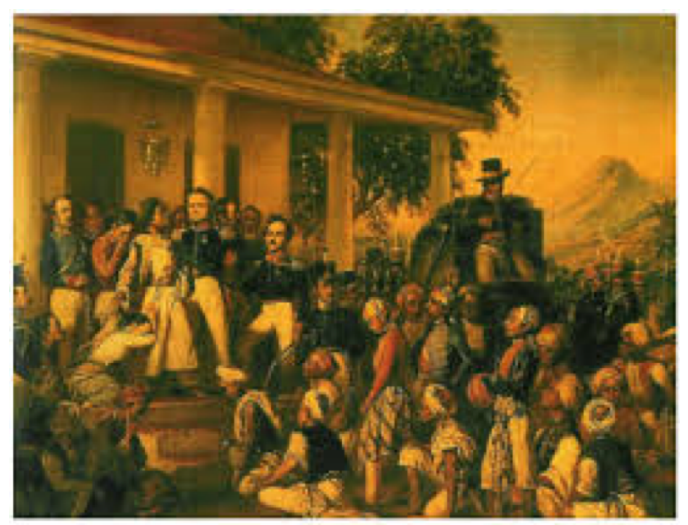

Gambar 1. Kisah Penangkapan Pangeran Diponegoro, karya Raden Saleh, tahun 1857 (Sumber Gambar:

http://upload.wikimedia.org/, diakses pada tanggal 02-03-2017)

Menurut pengertian umum atau awam, gambar merupakan media kering yang menggunakan material pensil atau pena yang biasanya dibubukan sebagai garis tunggal di suatu permukaan, sementara lukisan merupakan media basah yang menggunakan cat atau pigmen, yang dibubuhkan secara berlapis-lapis menggunakan kuas di suatu permukaan.

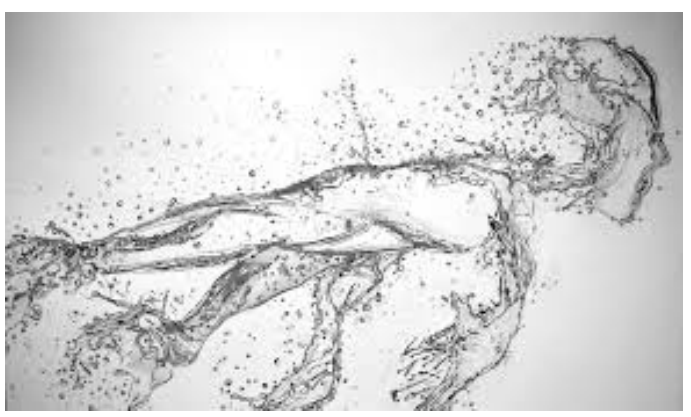

Gambar 2. Running Water, karya Paul Stowe, tahun pembuatan karya tidak diketahui (Sumber Gambar:

https://www.saatchiart.com/art/, diakses pada tanggal 02-03-2018

Paham orang dulu, ketika berbagai kepandaian dipandang berasal dari dewa-dewa (kitab Tantu Panggelaran abad XVI) tentang kerja 'melukis' difahami sebagai kerja mengatur atau menyusun rupa yang indah menurut wujud yang berasal dari cipta. (Yuliman, 2001:8). Dalam perkembangan seni rupa Indonesia, terdapat berbagai corak seni lukis yang mengingatkan pada tradisi menggambar yang tidak meniru kenyataan. Dalam bingkai kesenian tradisional, gambar lebih dikenal sebagai media ungkapan, dibandingkan lukisan. Gambargambar dalam bingkai seni rupa tradisioanl hampir tidak menyerupai kenyataan dan memperlihatkan deformasi. (Jim Supangkat, Drawing, 2001, hal. 69). Kita bisa melihatnya dalam karya seniman tradisi asal Gresik, almarhum Masmundari 
dengan cara pemggambaran yang polos atau naif, mendeformasi bentuk tubuh manusia secara keseluruhan, jauh dari kenyataan, tidak realistis. Gambar-gambar karya Masmundari, tampak bernarasi, ada yang diungkapkan oleh senimannya, tentang suatu kejadian atau peristiwa. Masmundari menggambar untuk lampion-lampion khas Gresik, Jawa Timur yang disebut damarkurung (lampu yang dikurung).

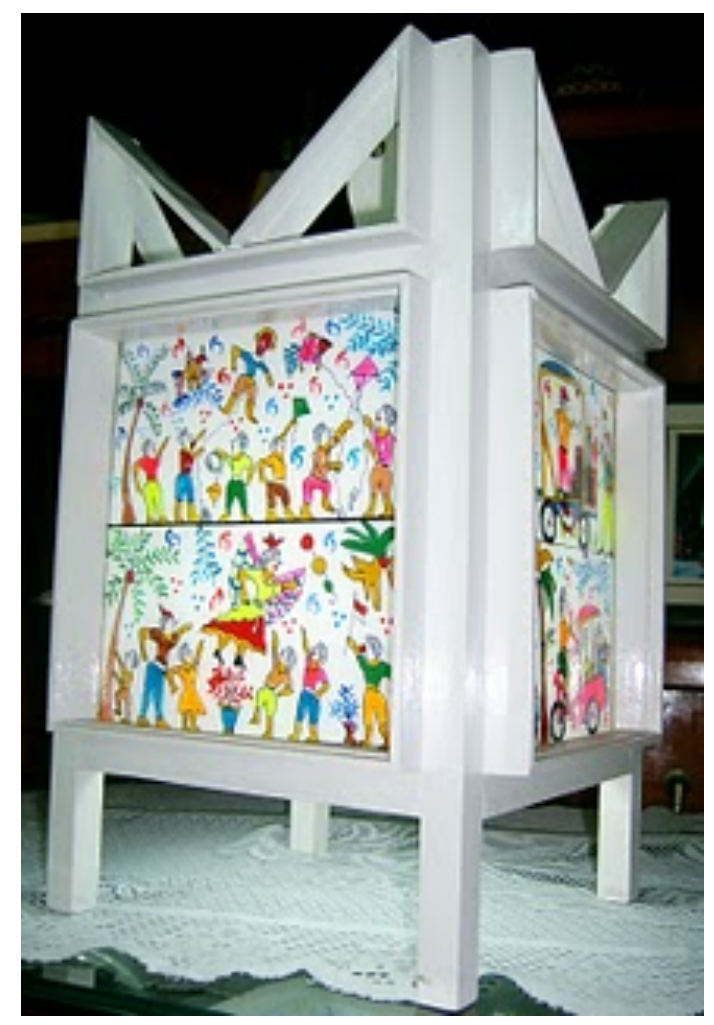

Gambar 3. Lampion Damarkurung karya Masmundari (Sumber Gambar: Katalog Pameran Seabad Masmundari

adalah berbeda dengan seni gambar dan keduanya meniliki keunggulan dan ciri khasnya masing-masing, sehigga tidak bisa dibedakan secara status atau derajat hirarki. Beragamnya karya seni, mengundang para peneliti untuk meneliti karya seni baik seni tradisi maupun non tradisi, mulai dari relief candi-candi, gambar atau lukisan primitif di guagua, karya sastra, karya lukis, fashion, foto dan lainnya. Kebutuhan penelitian tersebut harus didukung oleh cara pembacaan atau analisa dari suatu objek yang akan diteliti. Beragam cara pembacaan diantaranya semiotika, semantika, diskursus (discourse) hermeneutika, fenomenologi, psikoanalisis, dan bahasa rupa.

Makalah ini akan mengulas karya salah satu pelukis Indonesia, Erica Hestuwahyuni dengan pembacaan Bahasa Rupa yang diperkenalkan oleh Prof. Dr. Primadi Tabrani.

\section{LANDASAN TEORI}

Hasil karya seni baik seni rupa, musik, sastra, tari, film dan sebagainya, agar bisa dipahami dengan akurat untuk kepentingan penelitian, diperlukan cara pembacaan yang tepat. Beberapa cara pembacaan yang dibahas di dalam makalah ini antara lain semiotika, psikoanalisa, dan bahasa rupa.

\section{Bahasa Rupa}

Bahasa Rupa merupakah ilmu analisa pembacaan karya seni yang diperkenalkan pertama kali di Indonesia sekitar tahun 1980an oleh Prof. Dr. Primadi Tabrani, seorang pendidik senior di Fakultas Seni Rupa dan Desain, Institut Teknologi Bandung. Analisa cara bahasa rupa berguna untuk membaca gambar gua prasejarah, primitif, tradisi, serta 
gambar anak, walaupun gambargambar itu tanpa teks.

Bahasa rupa Primadi Tabrani, membedakan bahasa rupa Barat dengan dengan bahasa rupa tradisi. Makalah ini akan membahas ilmu baru ini secara lebih detil di sub bab Bahasa Rupa Primadi Tabrani.

\section{Bahasa Rupa Primadi Tabrani}

Bahasa rupa temuan Prof. Dr. Primadi Tabrani adalah untuk menganalisa karya seni tradisi atau ketimuran yang tidak bisa dibaca dengan sistem Barat yang selama ini dianggap universal. Perbedaan bahasa rupa Barat dan bahasa rupa tradisi tampak dalam relief di candicandi, wayang kulit, wayang beber, wayang golek, lukisan Bali, gambar pada lampion damarkurung (Gresik), gambar primitif di gua-gua, serta gambar atau lukisan anak, dimana cara penggambaran tokoh-tokoh pada karya-karya tersebut digambarkan secara utuh (dari kepala sampai kaki) tidak close up, . Karya seni tradisi cenderung naratif, bercerita dan ada kesan bergerak. Sementara bahasa rupa modern yang berkembang di Barat sejak jaman renaissans (Jakob Sumardjo, dalam Bahasa Rupa Primadi Tabrani, 2012, hal. 5) cara penggambarannya tanpa matra waktu, objek dipenjarakan dalam bingkai dan tidak bergerak, tokoh digambarkan close up. Primadi Tabrani menamai pembacaan bahasa rupa Barat dengan NPM (naturalisperspektip-momenopname) dan bahasa rupa pendahulunya (tradisi, primitif) dengan RWD (ruang waktu - datar). a. NPM (Naturalis-PerpektipMomenopname) (Primadi Tabrani, 2012, hal. 136)

- Naturalis : gambar merupakan deskripsi alam seperti apa adanya

- Perspektif : objek jauh digambarkan kecil, objek dekat digambarkan besar

- Momenopname :

- Dari satu arah, satu tempat, satu waktu

- Gambar mati (Still picture)

- Objek dipenjarakan dalam frame

- Gambar kehilangan matra waktu

- Bercerita dengan mimik wajah

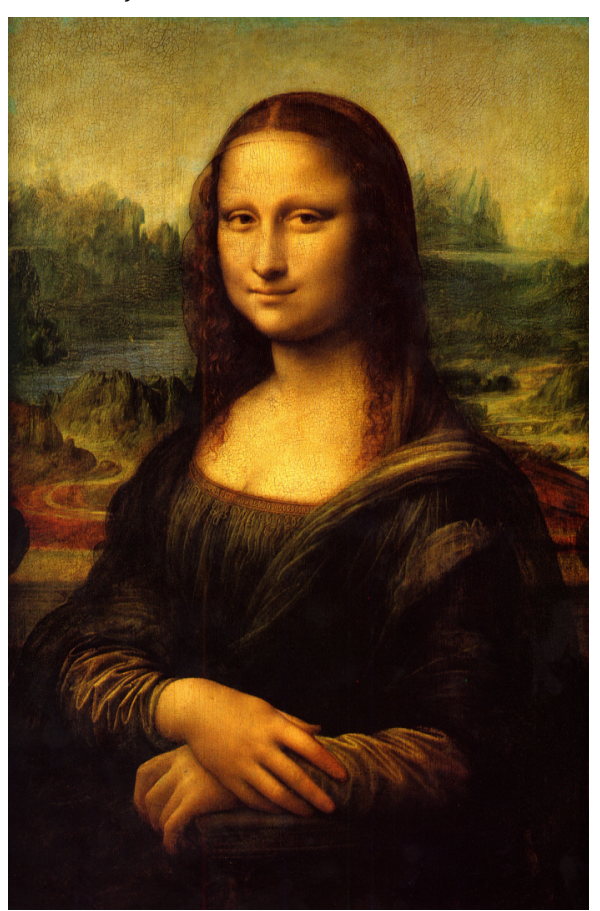

Gambar 4. Mona Lisa, karya Leonardo Davinci

b. RDW (Ruang -Waktu - Datar) (Primadi Tabrani, 2012, hal. 136). 
- Ruang : dari aneka arah, aneka jarak

- Waktu : bercerita, dari satu kejadian ke kejadian lain dalam satu bidang

- Datar : tanpa perspektif, tidak bervolume

- Bila dipentingkan, objek digambar lebih besar dari sekelilingnya

- Bercerita dengan gesture.

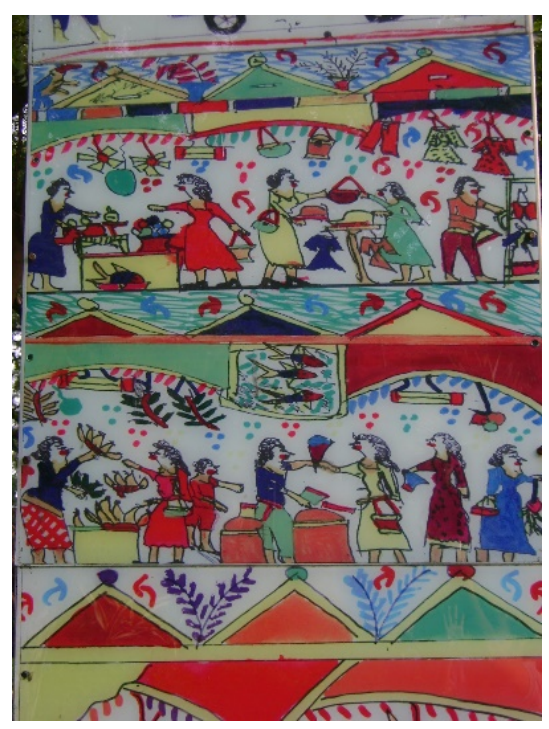

Gambar 5. Karya Masmundari

- Penggambaran dengan prinsip 'sinar $x^{\prime}$ : menembus objek yang sama digambar dalam satu bidang $\rightarrow$ objek bergerak dan berada pada aneka waktu dan tempat yang sedikit berbeda.

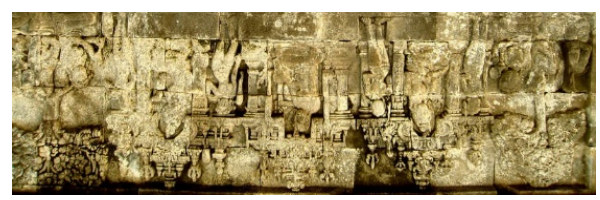

Gambar 6. Latitavistara

- Penggambaran cara luar angkasa: objeknya berbalik- balik - ada suatu yang berkeliling.

Dalam bahasa rupa dikenal istilah wimba dan cara wimba (Tabrani, 2012:30). Saneto Yuliman dalam buku Dua Seni Rupa, memperkenalkan istilah imba (isi wimba) berasal dari istilah Kawi (Jawa Kuno) yang berarti sosok atau bentuk. Lalu cara wimba digambarkan disebut inimba (Yuliman, 2001:4).

Cara menuyusn wimba, dibedakan menjadi :

- Tata Ungkap Dalam : cara menyusun wimba lengkap dengan wimbanya.

- Tata Ungkap Luar perubahan isi wimba, cara wimba lengkap dengan ata ungkapan dalam antara gambar satu ke yang berikut pada satu rangkaian gambar (komik, film, tv).

\section{Membaca Bahasa Rupa Anak}

Sebelum menjadi dewasa tentunya kita semua pernah menjadi anak-anak. Saat masih anak-anak, pemikiran-pemikiran kita masih jernih, naïf, dan spontan. Setiap anak tentunya akan berbeda sifat-sifat dan karakter pribadinya. Hal ini ditentukan oleh lingkungan anak tinggal dan bagaimana anak dibesarkan. Anak-anak sudah mampu berekspersi sejak mereka dilahirkan, yaitu dengan tangisan dan gestur yang disampaikannya. Sebelum anak mampu berbicara dan kenal tulis-menulis, anak 
menyampaikan pesan lepada orangtuanya lewat gestur atau bahasa tubuhnya, dan pada tahap awal yang mampu membaca bahasa tubuh anak adalah orang yang paling dekat dengan dirinya yaitu orangtuanya terutama ibunya. Begitupun sebaliknya, anak akan mengerti pesan yang disampaikan dari orangtuanya lewat gesturorangtuanya seperti senyuman, tatapan, gerakan tangan, pelukan. Walaupun anak-anak belum mengerti bahasa lisan orangtuanya, namun anak sudah mampu mengimajinaikan apa yang disampaikan orangtuanya.

Sejalan dengan tumbuh kembang anak, sebelum anak mengenal baca-tulis, ada saatnya anak-anak mampu berekspresi lewat karya seni salah satunya adalah dengan menggambar. Paparan pada bagian Pendahuluan telah dijelaskan bahwa dalam bingkai tradisi, gambar dikenal sebagai media ungkapan. Begitupun anak-anak, mereka bercerita dengan gambar melalui bahasa rupa. (Tabrani, 2014:201).

Sebelum ditemukannya ilmu bahasa rupa, banyak orang dewasa yang mendapat kesulitan membaca bahasa rupa anak, padahal kita semua pernah menjadi anak-anak. Ciri gambar anak ternyata berdekatan dengan gambar prasejarah, primitif dan tradisi, sehingga bisa dibaca dengan system RWD.

Gambar anak akan berkembang sesuai usia mereka. Makalah ini, tidak menjelaskan secara detil perkembangan gambar mereka untuk disetiap usia, tetapi memperlihatkan gambar anak pada tahap awal mereka memasuki lingkungan sosial di pendidikan awal 'kelompok bermain' yaitu di usia 2-4 tahun dan saat mulai memasuki masa kritis yaitu 12-14 tahun.

Mengikuti skema perkembangan gambar dan bahasa rupa anak yang disusun oleh Prof. Dr. Primadi Tabrani, anak usia 3-4 tahun, anak menggambar coreng moren dan mulai ada arti. Bahasa rupa anak pada usia ini seperti teknik ruang angaksa, aneka ruang, aneka waktu.

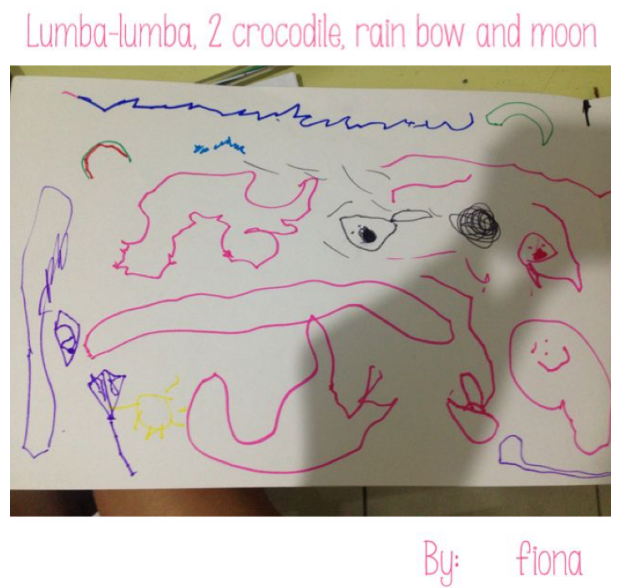

Gambar 7. Karya Fiona Hadi, 3.9 th. Teknik menggambar seperti ruang angkasa-berbalik-balik, berkeliling. Menurut Fiona, gambar itu menunjukan pelangi, lumba, lumba, dan buaya.

Aneka waktu: pelangi dan bulan. Aneka ruang-kebun binatang : lumba2 dan buaya .

(Sumber Gambar : Koleksi Penulis)

Memasuki usia 5-6 tahun, anak sudah mengenal konsep atas bawah, tepi bawah kertas sebagai garis tanah. 


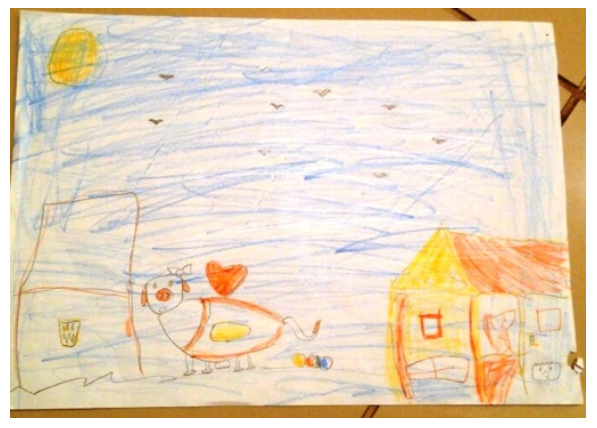

Gambar 8. Karya Georgiana, usia 6 tahun. Konsep atas bawah : rumah dibawah, tepi bawah kertas sebagai garis tanah.

(Sumber Gambar : Koleksi Penulis)

Cara menggambar anak usia 7 tahun, mengutamakan objek yang dipentingkan, objek yang penting diperbesar.

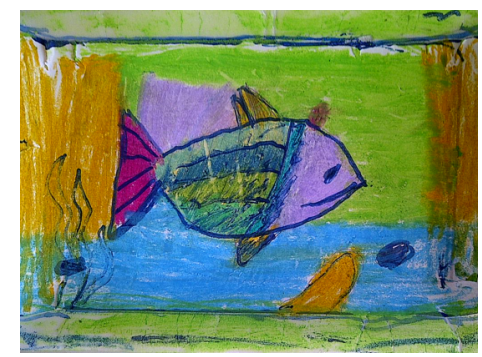

Gambar 9. Karya Darian, usia 7 tahun. Objek yg dipentingkan adalah ikan. Ini dikarenakan kakek Darian adalah penjual ikan hias.

(Sumber Gambar: Koleksi Penulis)

Usia 10-11 tahun, anak sudah mulai bisa merekam peristiwa. Seperti juga penelitian Howard Gardner :"Children aged eleven or twelve, are now able to remember stories accurately." (Gardner, 1981, hal. 139).

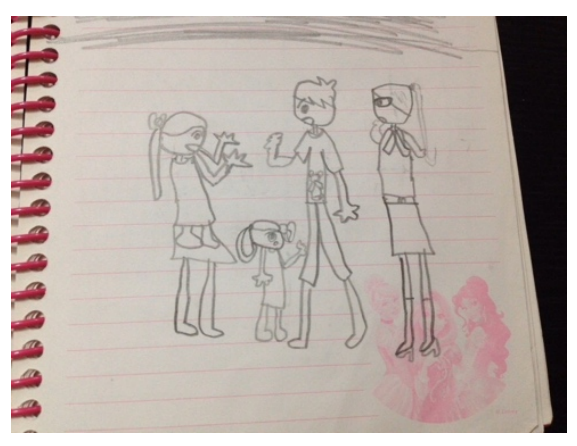

Gambar 10. Karya Gabriela, usia 10 tahun. Tampak tokoh-tokoh yang ada dalam gambar sedang berbicara : merekam peristiwa.

(Sumber Gambar: Koleksi Penulis)

Pada usia 11-13 tahun, disini anak sudah mulai memasuki tahap remaja, dan sudah punya kemampuan menganalisa dengan lebih tajam.

"Children have now clearly mastered the rules of their own language and the other symbol systems of their culture. [...] children are seduced by surface features (what individuals wear, where they live) and correlatively insensitive to less superficial features of the story..." (Gardner, 1981:138-139)

Disini mereka mengalami masa krisis (Tabrani, 2014:106), karena mendapatkan berbagai informasi. Ciri bahasa rupanya, mulai muncul gambar ruang tumpang tindih, kebingunan antara system RWD dan system NPM. Hal ini bisa disebabkan, di usia ini mereka mendapatkan pelajaran menggambar sistem Barat, namum berusaha untuk mengugkapan cerita peristiwa, yang bisa diungkapkan dengan system RWD. Masa ini 
adalah peralihan dari anak menjadi remaja, sehingga mereka mengalami kebingungan.

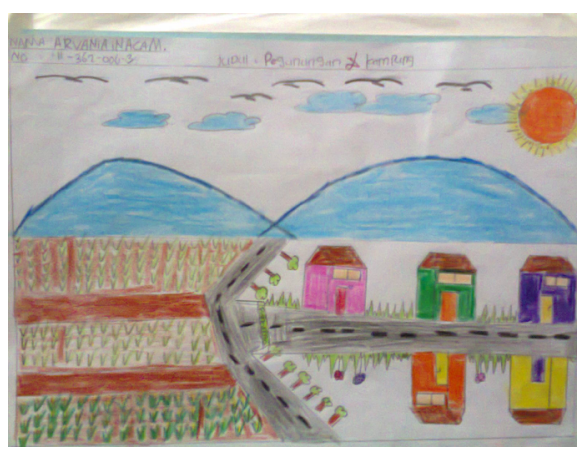

Gambar 11. Karya Arvania Inaca M. (11 tahun, kelas VI). Contoh gambar menunjukan, bahwa hasil gambar anak ini merupakan hasil gambar 'ajar'. Sumber Gambar : Internet

\section{METODE PENELITIAN}

Penelitian dilakukan secara kualitatif dengan pendekatan hermeneutic dimana penulis melakukan analisa dan penafsiran terhadap beberapa karya Erica Hestuwahyuni, beberapa karya anak, serta beberapa karya seniman lain sebagai pembanding. Hermeneutika sebagai sebuah metode yang erat terkait dengan bahasa, yaitu sebuah ilmu tentang menginterpretasikan (menafsirkan) yang umumnya untuk menafsirkan teks kitab suci, sastra, dan filsafat (AlHafizh ; Pengertian Hermeneutika). Pada penelitian ini, tafsir dilakukan terhadap suatu karya rupa yang bukan teks, namun karya rupa tersebut mengandung narasi serupa cerita. Kemudian karya rupa tersebut dianalisa dengan pembacaan bahasa rupa. Teknik pengumpulan data yaitu melalui observasi langsung karya Erica Hestuwahyuni dengan mengunjungi studionya dan observasi beberapa gambar anak usia 4 - 10 tahun yang penulis peroleh secara langsung dari beberapa rekan dan keluarga yang mempunyai anak, serta beberapa data diperoleh dari internet. Data gambar yang diperoleh selanjutnya dianalisa dan untuk memperkuat analisa dilakukan wawancara langsung terhadap subjek yang diteliti, tujuannya adalah untuk mendapat konfirmasi dari interpretasi penulis. Hasil dari wawancara langsung, terdapat beberapa interpretasi yang berbeda antara pembacaan karya oleh pengamat (dalam hal ini penulis) dengan yang dimaksud oleh subjek yang diteliti.

\section{ANALISA KARYA ERICA HESTUWAHYUNI}

Erica Hestuwahyuni lahir di Yogyakarta .pada tahun 1971. Mulai melukis sejak sekolah dasar dengan bergabung di Sanggar Katamsi, dengan bimbingan Suharto PR dan Herry Wibowo, keduanya pelukis mapan. Kemudian melanjutkan studinya di ISI Yogyakarta, namun tidak selesai, lalu ia belajar ke Rusia, di Surikov Institute of Art. Karyakaryanya yang berwarna cerah dan bergaya lukis kanak-kanak, sehingga banyak sekali peminatnya.

Berdasarkan uraian toeri bahasa rupa Primadi Tabrani, tampak jelas bahwa cara menggambar Erica, adalah caa menggambar anak. Apabila menggunakan teori psikoanalisa Carl Jung, bahwa setiap manusia memiliki ketidaksadaran kolettif (collective 
unconscious) (Irma Damajanti, 2006:17) ada kecenderungan bagi beberapa seniman yang menggambar dengan cara anak, padahal mereka berbeda geografis atau berbeda tempat tinggal. Seniman-seniman tersebut diantaranya selain Erica dan Masmundari diantaranya yang berasal dari Indonesia adalah Heri Dono, Eddie Hara, Yunizar, lalu ada Paul Klee seniman kelahiran Swiss . Karya-karya mereka memang berbeda secara tampilan namun cara penggambarannya hampir sama, yaitu berdasarkan seni tradisi dan cara penggambaran anak.

\section{Karya Prosperity Wedding}

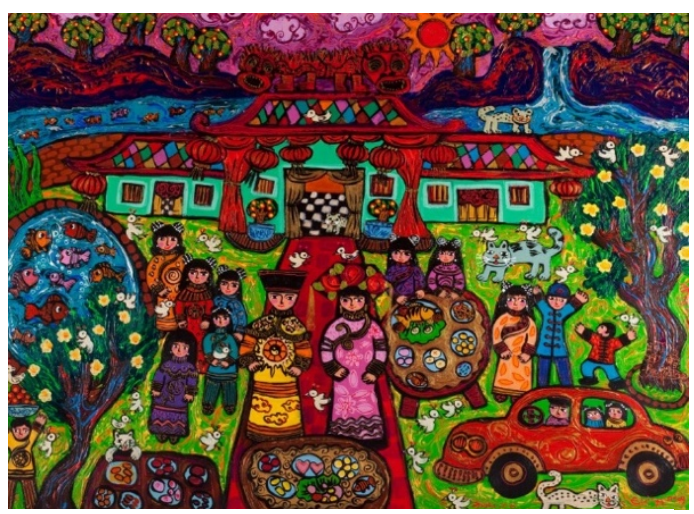

Gambar 12. Prosperity Wedding (Sumber Gambar:

http://www.artfront.com.sg/artists/ericawahyuni/\#2, diambil pada tanggal 03-032017)

\section{Unsur-unsur Bahasa Rupa}

1. Karya diatas, tampak seperti karya anak-anak, yang playful, naif, ceria, penuh warna yang berani. Namun dilihat dari kelengkapan informasi yang ditampilkan dalam karya ini (unsur budaya,: kostum, kuliner, bangunan) jelas bukan karya anak-anak.
2. Pelukisnya dipastikan berusia 1113 tahun keatas, saat usia tersebut, pada gambar, mulai tampak gambar ruang yang tumpang tindih, dan bingung antara RWD dan NPM. (baca sub-bab Bahasa Rupa Anak di makalah ini) .

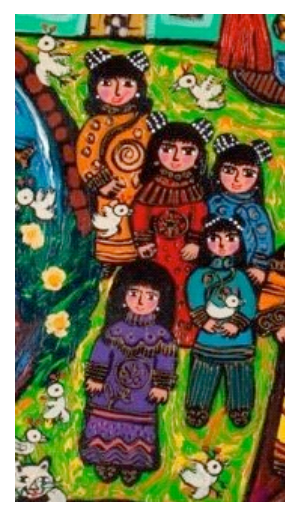

Gambar 13. Penggambaran wimba anak, nampak tumpang tindih (Sumber Gambar:

http://www.artfront.com.sg/artists/eric a-wahyuni/\#2, diambil pada tanggal 03-03-2017)

3. Wimba orang digambarkan utuh, tanpa close up, utuh dari kepala sampai kaki. Wimba pasangan pengantin tampak lebih besar dari wimba orang lainya, karena itu yang dipentingkan.

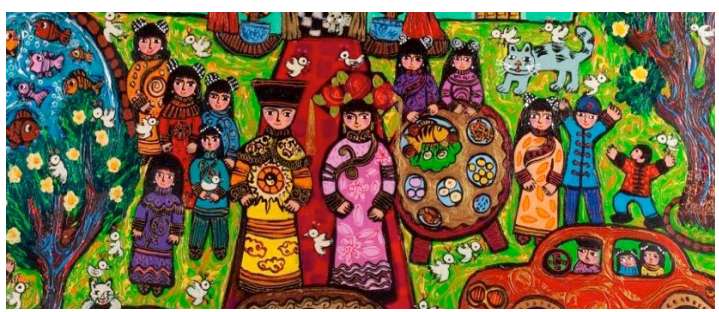

Gambar 14. Cropping dari gambar utuh (Sumber Gambar:

http://www.artfront.com.sg/artists/ericawahyuni/\#2, diambil pada tanggal 03-03-

2017) 
4. Wimba orang ada yang yang tampak dinamis yaitu dengan mengangkat kedua tangannya, ada yang statis dengan senyum.

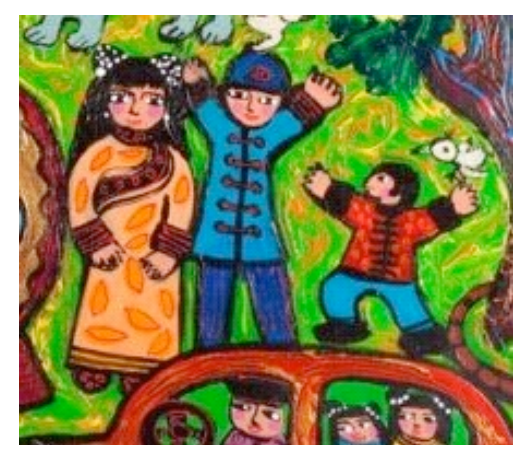

Gambar 15. Anak mengangkat tangan

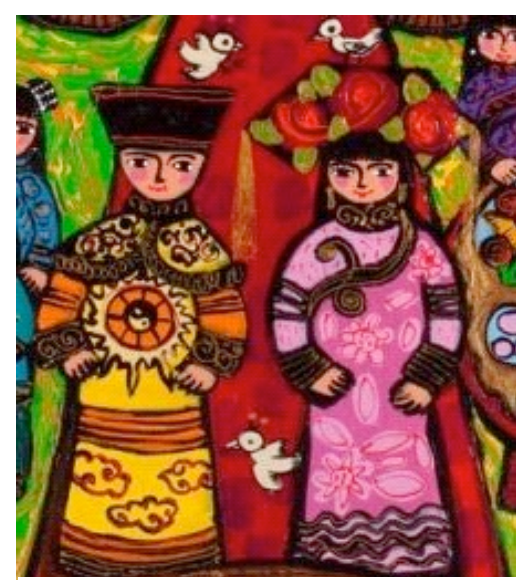

Gambar 16. Pasangan Tersenyum

5. Wimba waktu digambarkan dengan tanda matahari dan awan, menandakan siang hari dengan matahaeri cerah namun berawan.

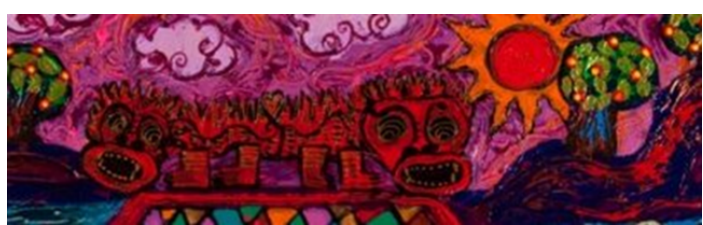

Gambar 17. Langit digambarkan tidak berwarna biru, tapi seniman membebaskan warnanya menjadi warna agak keunguan (magenta). Hasil wawancara penulis dengan seniman,
6. Wimba bukan orang : meja makan, kolam ikan, rumah, sungai, mobil, pohon, digambarkan datar tanpa perspektif (datar-RWD). Walau tampak atas (bird's eyes view namun melanggar formula perspektif)

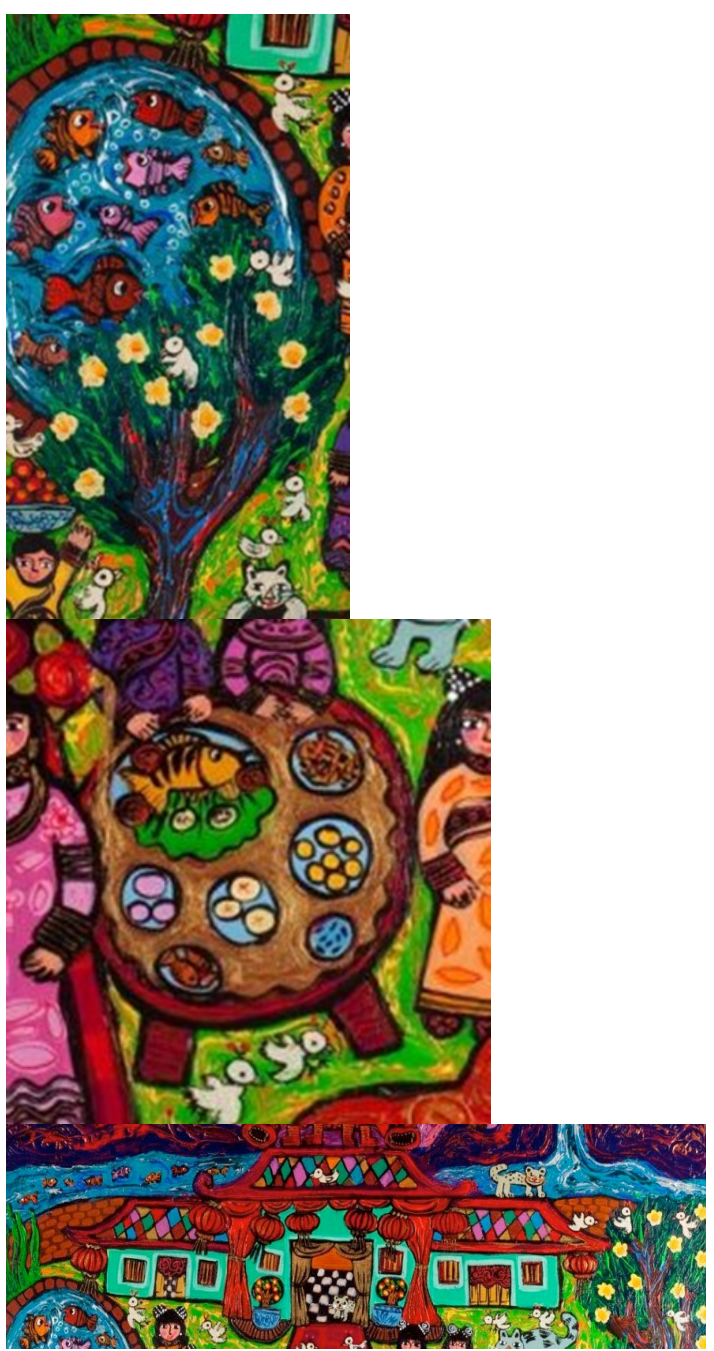

Gambar 18. Rumah tampak depan tanpa volume, namun sungai tampak atas, melanggar aturan perspektif

7. Wimba ruang, digambarkan outdoor, pesta diadakan di luar Wimba ruang, digambarkan 
outdoor, pesta diadakan di luar rumah.

8. Cara penyusunan wimba, adalah tata ungkap dalam : Komposisinya memusat, wimba orang menjadi sentral. Wimba pengantin jadi pusat perhatian (lebih besar), dipentingkan.

9. Horison dalam gambar, tampak ada tiga horizon, yaitu :

Bawah : lansekap kebun

Tengah : lansekap sungai dan pepohonan

Atas : lansekap langit

\section{SIMPULAN}

Berdasarkan uraian pembacaan diatas, tampak karya Erica terinspirasi dari gaya penggambaran tradisi lokal dan penggambaran cara anak.

Karya Erika bisa dibaca secara RWD (ruang-waktu-datar)

- Ruang: ditandai dengan suasana outdoor

- Waktu ditandai dengan : matahari -siang hari, berawan: banyak awan dan langit berwarna tidak terang walaupun tidak gelap (mendung)

- Datar : tidak ada perspektif pada cara penggambaran wimba-wimbanya.

Karya tersebut mengandung unsur-unsur bahasa rupa :

- Estetis : tampilan karya indah

- Simbolis : mengandung unsur-unsur budaya
- Bercerita : narasi tampak sangat jelas, yaitu suasana perkawinan yang mewah, dengan aneka makanan, ada mobil, ada rumah mewah,. Narasi pada gambar ini, sangat kuat, sehingga tanpa dibubuhi judul karya Prosperity Wedding pun, karya ini sudah sangat bercerita

Menelaah teori psikoanalisa tentang kreativitas bahwa manusia memiliki ketidaksadaran kolektif dan kesadaran kolektif, menunjukan bahwa seniman memiliki suatu bakat kolektif yaitu kemampuan menggambar yang juga banyak dimiliki oleh seniman lain. Ketrampilannya lantas dikembangkan dengan proses sadar, proses latihan dan belajar, sehingga karya-karyanya membawanya pada kesadaran kolektif.

Gambar-gambar Erica yang konsisten, dan sangat mudah ditebak, sehingga pengamatnya tak perlu berpikir keras untuk mengetahui pesan dibalik karyanya, menunjukan bahwa Erica adalah sosok yang santai, apa adanya, bukan sosok yang complicated, walaupun karya-karyanya digambarkan cukup detil, tapi tidak rumit.

Pembubuhan judul pada karyakaryanya yang nampak sederhana dan hanya ada perubahan kata-kata dalam beberapa karya yang lain dengan tampilan yang dibuat seperti beberapa seri, memberi penafsiran energi yang luar biasa dari seniman, menggambar adalah kesehariannya, 
dan ia tidak suka membuat karya yang nampak 'complicated' .

\section{REFERENSI}

Darmajanti, Irma, 2006, Psikologi Seni, Kiblat

Gardner, Howard, 1981, Children's Perceptions of Work of Art : A Developmental Portrait dalam David O'Hare: Psychology And The Arts, The Harvester Press Ltd

Tabrani, Primadi, 2012, Bahasa Rupa, Kelir, Indonesia

Tabrani, Primadi, 2014, Proses Kreasi, Gambar Anak, Proses Belajar, Erlangga, Indonesia.

Supangkat, Jim, 1995, Tentang Seni Lukis dan Seni Gambar, Katalog Pameran Drawing, The Jakarta Post.

Yuliman, Saneto, 2001, Dua Seni Rupa : Sepilihan Tulisan, Yayasan Kalam. 